\title{
Long-term variations in ocean acidification indices in the Northwest Pacific from 1993 to 2018
}

\author{
Miho Ishizu ${ }^{1,2}$ (D) Yasumasa Miyazawa ${ }^{3} \cdot$ Xinyu Guo $^{4}$
}

Received: 27 December 2020 / Accepted: 2 October 2021 / Published online: 28 October 2021

(c) The Author(s) 2021

\begin{abstract}
Long-term variations in ocean acidification indices in the Northwest Pacific were examined using observational data and a biogeochemical model with an operational ocean model product for the period 1993-2018. The model and observational data for the surface ocean ( $<100-m$ depth) exhibit consistent patterns of ocean acidification in the subtropical and Kuroshio Extension regions and relative alkalinization (i.e., reduced acidification) in the subarctic region of the Northwest Pacific. Below 100-m depth, acidification dominated in the subtropical regions and alkalinization in the subarctic regions. We attribute the excess acidification in the subtropical and Kuroshio regions to the vertical mixing of dissolved inorganic carbon (DIC) exceeding the DIC release by air-sea exchange. These regional differences in acidification and alkalinization are attributed to spatially variable biological processes in the upper ocean and horizontal and vertical physical redistribution of DIC. Our model and observational results have implications for the spatial extent and pattern of ocean acidification, along with the strength of the ocean carbon sink, which are key aspects of global climate change.
\end{abstract}

Keywords Biogeochemical model · Northwest Pacific · Ocean acidification · Ocean alkalinization · JCOPE

Miho Ishizu

mishizu@pusan.ac.kr

Yasumasa Miyazawa

miyazawa@jamstec.go.jp

Xinyu Guo

guoxinyu@sci.ehime-u.ac.jp

1 Center for Climate Physics, Institute for Basic Science, Busan 46241, Republic of Korea

2 Pusan National University, Tonghapgigyegwan Bldg 2 Busandaehak-ro, 63 beon-gil,

Geumjeong-gu, Busan 46241, Republic of Korea

3 The Japan Agency for Marine-Earth Science and Technology, Environmental Variability

Prediction and Application Research Group, Yokohama Institute for Earth Sciences, 3173-25

Showa-machi, Kanagawa-ku, Yokohama 236-0001, Japan

4 Center for Marine Environmental Studies, Ehime University, 2-5 Bunkyo-cho,

Matsuyama 790-8577, Japan 


\section{Introduction}

The atmospheric partial pressure of $\mathrm{CO}_{2}\left(\mathrm{pCO}_{2}\right.$, air) has been increasing at a rate of $\sim 1.8$ parts per million by volume (ppmv) per year in recent decades, which is a consequence of human activities such as fossil fuel burning, deforestation, and cement production (Takahashi et al. 2009; IPCC 2013). The contemporary global ocean now acts as a net sink of anthropogenic $\mathrm{CO}_{2}$, but this net flux reflects an imbalance between regions of $\mathrm{CO}_{2}$ outgassing and uptake. In general, the subtropics act as a source for $\mathrm{CO}_{2}$ and the subarctic is a sink (Takahashi et al. 2009), but there is strong regional and temporal heterogeneity in the air-sea $\mathrm{CO}_{2}$ flux, because the sea surface $\mathrm{CO}_{2}$ concentration is affected by ocean circulation (subduction and obduction; Toyama et al. 2017; Ono et al. 2019; Ishii et al. 2020) and biological activity (Takahashi et al. 2002; Yasunaka et al. 2013). As such, the sea surface $\mathrm{CO}_{2}$ concentration can become higher than that of the atmospheric $\mathrm{CO}_{2}$ concentration, and vice versa depending on the regional internal oceanic processes. Interannual and decadal variations in the climate system can also alter the patterns of mean-state $\mathrm{CO}_{2}$ flux between ocean and atmosphere, and on longer time scales, anthropogenic perturbations to the ocean's physical and chemical state may adjust the spatial patterns of $\mathrm{CO}_{2}$ flux.

The uptake of anthropogenic $\mathrm{CO}_{2}$ by seawater changes the natural chemical equilibrium of the seawater $\mathrm{CO}_{2}$-carbonate system, resulting in ocean acidification (Bates et al. 2014). In the Northwest Pacific, Midorikawa et al. (2010) estimated surface $\mathrm{pH}_{25}$ trends from a 25 -year time-series along the $137^{\circ} \mathrm{E}$ line south of $35^{\circ} \mathrm{N}$ using observational data from the Japan Meteorological Agency (JMA). The results revealed that $\mathrm{pH}_{25}$ decreased by $0.0013 \pm 0.0005 \mathrm{yr}^{-1}$ in summer and $0.0018 \pm 0.0002 \mathrm{yr}^{-1}$ in winter from 1983 to 2007 . Wakita et al. (2013) investigated variations in ocean acidification during winter in the subarctic Northwest Pacific from 1997 to $2011\left(\mathrm{~K} 2=47^{\circ} \mathrm{N}, 160^{\circ} \mathrm{E}\right.$; KNOT $\left.=44^{\circ} \mathrm{N}, 155^{\circ} \mathrm{E}\right)$ and found that $\mathrm{pH}_{\text {in situ }}$ in the winter mixed layer decreased at a rate of $-0.0011 \pm 0.0004 \mathrm{yr}^{-1}$, which was lower than the average rate in the subtropical region $\left(-0.002 \mathrm{yr}^{-1}\right.$; Midorikawa et al. 2010). Their results revealed a decline in $\mathrm{pH}_{\text {in situ }}$ at a rate of $-0.0051 \pm 0.0010 \mathrm{yr}^{-1}$ between 200 and $250 \mathrm{~m}$ below the mixed layer, which corresponds to the density zone of $26.9 \sigma_{\theta} \mathrm{kg} \mathrm{m}^{-3}$, and is greater than any previously reported $\mathrm{pH}_{\text {in situ }}$ decrease in the surface layer in the open North Pacific.

Monitoring for biogeochemical variables including ocean acidification is important for understanding future ocean chemistry and the health of marine organisms and ocean ecosystems. Chemical variables related to the oceanic carbonate cycle are currently being monitored in several ongoing projects to determine whether the rate of ocean acidification can be identified from $\mathrm{pH}$ changes and other variables in the open ocean (Bates 2007; Gonzalez-Davila et al. 2007; Dore et al. 2009; Olafsson et al. 2009; Midorikawa et al. 2010; Bates et al. 2014; Carter et al. 2017; Chen et al. 2017; Wakita et al. 2013). However, making synoptic- to basin-scale inferences from such ocean acidification studies is challenging due to the sparsity of $\mathrm{pH}_{\text {in situ }}$ measurements $\left(\mathrm{pH}_{25}\right)$ in time and space.

Our current understanding of ocean acidification at present is based on time-series $\mathrm{pH}$ measurements at several fixed monitoring stations (Bates 2007; Gonzalez-Davila et al. 2007; Dore et al. 2009; Olafsson et al. 2009; Midorikawa et al. 2010; Bates et al. 2014; Wakita et al. 2013). As such, a robust three-dimensional overview of basin-scale ocean acidification is currently unavailable.

The Japan Coastal Ocean Predictability Experiment (JCOPE; http://www.jamstec.go.jp/ jcope/) model was developed to integrate the sparse observational constraints and simulations of ocean physics. JCOPE is an operational eddy-resolving ocean physical model 
(Miyazawa et al. 2017, 2019) that incorporates observational data from floats, satellites, and shipboard measurements. Several studies have successfully used the JCOPE model product to study ocean dynamics, including 10-yr oceanic variations (Miyazawa et al. 2009, 2017; Saeyanto et al. 2014; Chang et al. 2015; Miyama et al. 2021). Using the JCOPE reanalysis model products as the physical background, Ishizu et al. (2019, 2020) recently developed an offline biogeochemical model (JCOPE_EC). The model includes the carbon cycle and state variables related to ocean acidification indices. The results showed that the model reliably reproduces the distributions of the biogeochemical state variables (DIN, DIC, and ALK) on a seasonal scale (Ishizu et al. 2019, 2020).

In this study, we examined the recent trends of long-term (i.e., multi-decadal) variations in the inorganic marine carbon cycle, using JCOPE_EC. In Sect. 2, details of the model and data are described. Section 3 presents the results of the multi-decadal simulations of the ocean acidification indices, and a comparison between the available observational data and model outputs. In Sect. 4, air-sea $\mathrm{CO}_{2}$ fluxes and potential mechanisms of the multidecadal variations in ocean acidification are discussed. Finally, the conclusions are presented in Sect. 5.

\section{Model and data}

JCOPE_EC (Ishizu et al. 2019, 2020) is an off-line tracer model driven by physical processes simulated by an operational eddy-resolving ocean general circulation model (JCOPE2M; Miyazawa et al. 2017, 2019), which is based on the Princeton Ocean Model with a generalized sigma coordinate (Mellor 2001). The model is a three-dimensional regional model covering the Northwest Pacific $\left(10.5^{\circ}-62^{\circ} \mathrm{N}, 108^{\circ}-180^{\circ} \mathrm{E}\right)$ with a horizontal resolution of $1 / 12$ of a degree $(4.4-9.1 \mathrm{~km})$ and 46 active vertical levels. The set-up of the carbon cycle in the model is the same as the general form of the OCMIP protocol (Orr et al. 1999). The JCOPE_EC model calculates $\mathrm{pCO}_{2}$ based on temperature, salinity, DIC, and ALK (Ishizu et al. 2019, 2020). The atmospheric $\mathrm{CO}_{2}$ values are obtained from an empirical formula based on observational data (Ishizu et al. 2019). The reproducibility of the model output above 500-m depth has been demonstrated for the seasonal carbon cycle (Ishizu et al. 2020).

The model was driven by forcing from daily oceanic (JCOPE2M) and six-hourly atmospheric (NCEP/NCAR) reanalysis data from 1993 to 2018, yielding an analysis period of 26 years. The initial concentrations of phytoplankton were set to 0.1 and $0.0 \mathrm{mmol} \mathrm{m}^{-3}$ for depths above and below $150 \mathrm{~m}$, respectively. The initial zooplankton concentrations were set to $10 \%$ of the phytoplankton concentrations. The initial detritus concentration was set to $0.0 \mathrm{mmol} \mathrm{m}^{-3}$. Dissolved inorganic nitrogen (DIN) and phosphate (DIP), and DIC were initialized using the monthly climatological data for January, and ALK was initialized using the annual climatology at the beginning of the model run (Ishizu et al. 2019, 2020). The boundary conditions were set using the monthly climatology for DIN, DIP, and DIC, and the annual climatology for ALK (Ishizu et al. 2019, 2020). JCOPE_EC is described in more detail in Ishizu et al. (2019, 2020).

Temperature, DIC, and ALK drive the annual variations in ocean acidification indices, but DIC exerts the strongest influence. We used observational profiles to confirm that changes in $\mathrm{pH}_{\text {in situ }}\left(\mathrm{pH}_{25}\right.$ and $\left.\Omega_{\text {arg }}\right)$ are primarily linked to changes in DIC (not shown). To validate the reproducibility of the long-term variations in ocean acidification from the model, we compared observations of DIC from 1999 to 2018 with the model outputs along 
the same section (line $165^{\circ} \mathrm{E}$ ) in Sect. 3.2. There are no available observations of ALK that encompass at least a 10-year interval within the target period from 1999 to 2018.

The observational data for 2017 and 2018 along line $165^{\circ} \mathrm{E}$ were obtained from the Japan Meteorological Agency (JMA; https://www.data.jma.go.jp/kaiyou/db/vessel_obs/ data-report/html/ship/ship.php), and the data for 1992, 2000, and 2006 were obtained from PACIFic ocean Interior Carbon (PACIFICA; https://climatedataguide.ucar.edu/climatedata/pacifica-pacific-ocean-interior-carbon) dataset. Monitoring data from line $165^{\circ} \mathrm{E}$ in the Northwest Pacific were used for the analysis described in Sect. 3.2.

The temporal variations in DIC calculated from the model were relatively large between 1993 and 1998 (Appendix), but became stable after 1999. Therefore, we regard 1993-1998 to be a spin-up period, and only use the model outputs after 1999 for the analysis (Figs. 2, 3 and $6,7,8,9,10,11$; Table 1). We use the following equation to quantify the rate of change in state variables $\mathrm{C}$ (x, y, z, and t) from 1999 to 2018 in Sect. 3.1:

$$
\mathrm{C}(\mathrm{x}, \mathrm{y}, \mathrm{z}, 2018-1999)=(<\mathrm{C}(\mathrm{x}, \mathrm{y}, \mathrm{z}, 2018)>-<\mathrm{C}(\mathrm{x}, \mathrm{y}, \mathrm{z}, 1999)>) /(2018-1999+1)
$$

where $<>$ denotes the annual mean of the state variable for the specified year. We also calculated linear trends for DIC, $\mathrm{pH}_{\text {in situ }}, \mathrm{pH}_{25}$, and $\Omega_{\text {arg }}$ at each depth in each region (Table 1; Appendix Fig. 13), using the annual mean values for every year, which is different from the calculation method of Eq. (1).

Table 1 Averaged trends of model outputs in DIC, $\mathrm{pH}_{\mathrm{insitu}}, \mathrm{pH}_{25}$ and $\Omega_{\text {arg }}$ at each depth in the subarctic region $\left(155^{\circ}-175^{\circ} \mathrm{E}, 40^{\circ}-50^{\circ} \mathrm{N}\right)$, Kuroshio Extension $\left(142^{\circ}-175^{\circ} \mathrm{E}, 30^{\circ}-40^{\circ} \mathrm{N}\right)$ and subtropical region $\left(130^{\circ}-175^{\circ} \mathrm{E}, 15^{\circ}-30^{\circ} \mathrm{N}\right)$, respectively. Colors denote the strength of the values, which are determined by the maximum and minimum values in each variable

\begin{tabular}{cccccc}
$\mathrm{d}(\mathrm{DIC})(\mathrm{umol} / \mathrm{kg} / \mathrm{yr})$ & \multicolumn{1}{c}{ ) } & \multicolumn{1}{c}{ (00 } & 500 & 1000 \\
\hline Depth $(\mathrm{m})$ & 0 & -0.08 & -0.53 & -0.87 & -0.87 \\
\hline Subarctic region & 0.26 & 0.27 & -0.52 & -0.69 & -0.63 \\
Kuroshio Extension & 0.85 & 1.03 & 0.50 & 0.67 & -0.07 \\
Subtropical region & 1.13 & & & \\
\hline $\mathrm{d}_{\left(\mathrm{pH}_{\text {insitu }}\right)(/ \mathrm{yr})}$ & & 100 & 200 & 500 & 1000 \\
\hline Depth $(\mathrm{m})$ & 0 & -0.0009 & 0.0003 & 0.0012 & 0.0014 \\
\hline Subarctic region & -0.0015 & -0.0008 & 0.0004 & 0.0007 & 0.0006 \\
Kuroshio Extension & -0.0013 & -0.0017 & -0.0009 & -0.0016 & 0.0004 \\
Subtropical region & -0.0020 & & & &
\end{tabular}

\begin{tabular}{cccccc}
$\mathrm{d}\left(\mathrm{pH}_{25}\right)(/ \mathrm{yr})$ & \multicolumn{7}{c}{} \\
\hline Depth $(\mathrm{m})$ & 0 & 100 & 200 & 500 & 1000 \\
\hline Subarctic region & -0.0010 & -0.0003 & 0.0006 & 0.0012 & 0.0012 \\
Kuroshio Extension & -0.0013 & -0.0004 & 0.0009 & 0.0010 & 0.0010 \\
Subtropical region & -0.0012 & -0.0015 & -0.0009 & -0.0016 & 0.0003 \\
\hline
\end{tabular}

\begin{tabular}{cccccc}
$\mathrm{d}\left(\Omega_{\text {arg }}\right)(/ \mathrm{yr})$ & 0 & 100 & 200 & 500 & 1000 \\
\hline Depth $(\mathrm{m})$ & 0 & -0.0006 & 0.0016 & 0.0012 & 0.0005 \\
Subarctic region & -0.0042 & -0.0015 & 0.0029 & 0.0016 & 0.0005 \\
Kuroshio Extension & -0.0069 & -0.0034 & -0.0034 & -0.0024 & 0.0001 \\
Subtropical region & -0.0090 &
\end{tabular}




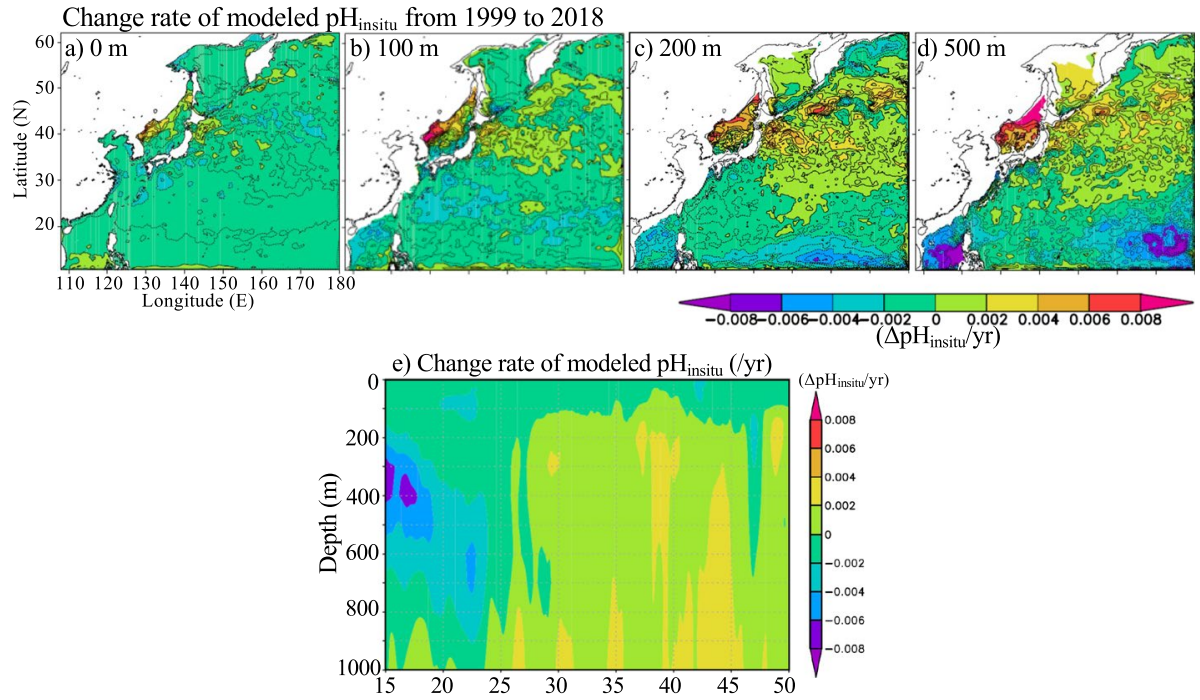

Fig. 1 a-d Horizontal distributions of the rate of modeled $\mathrm{pH}_{\text {in situ }}$ change from 1999 to 2018 at $0,100,200$, and $500 \mathrm{~m}$ depth. The annual values in 1999 were subtracted from those in 2018. e Vertical sections of the rate of modeled $\mathrm{pH}_{\text {in situ }}$ change along $165^{\circ} \mathrm{E}$ from 1999 to 2018

\section{Results}

\subsection{Long-term variations in ocean acidification indices obtained from JCOPE_EC}

The rates of change in the ocean acidification index $\left(\mathrm{pH}_{\text {in situ }}\right)$ obtained from JCOPE_EC are shown in Fig. 1. The surface $\mathrm{pH}_{\text {in situ }}$ declined by $0.002 \mathrm{yr}^{-1}$ over most of the study area, which means that ocean acidification is occurring over most of the surface Northwest Pacific (Fig. 1a). However, their rate changes are locally different. Prominent areas of ocean acidification (rate of change of $\mathrm{pH}_{\text {in situ }}=-0.002$ to $-0.004 \mathrm{yr}^{-1}$ ) exist off the Honshu and Ryukyu islands along Kuroshio $\left(25^{\circ}-38^{\circ} \mathrm{N}, 125^{\circ}-145^{\circ} \mathrm{E}\right)$ and at the polar front region $\left(38-42^{\circ} \mathrm{N}, 150-175^{\circ} \mathrm{E}\right)$.

Acidification is more significant at increasing depth and occurs further south at depths below $100 \mathrm{~m}$ (Fig. $2 \mathrm{~b}-\mathrm{d}$ ). The rate of change in $\mathrm{pH}_{\text {in situ }}$ is $\leq-0.002 \mathrm{yr}^{-1}$ in the surface layer and -0.002 to $-0.004 \mathrm{yr}^{-1}$ at a depth of $100 \mathrm{~m}$ (Fig. 1b). $\mathrm{pH}_{\text {in situ }}$ increases (i.e., alkalinization) are also evident in some regions (Fig. 1b-d), although the areas showing $\mathrm{a} \mathrm{pH}_{\text {in situ }}$ increase at the surface are very limited in extent (Fig. 1a). Large increases in $\mathrm{pH}_{\text {in situ }}$ occur in the northern Japan Sea and subarctic region $\left(35^{\circ}-40^{\circ} \mathrm{N}, 140^{\circ}-150^{\circ} \mathrm{E}\right.$; Fig. 1b). The boundary between ocean acidification and alkalinization occurs at around $35^{\circ} \mathrm{N}$, corresponding to the Kuroshio Extension area at a depth of $100 \mathrm{~m}$ (Fig. 1b), but the boundary is further south at around $15^{\circ}-20^{\circ} \mathrm{N}$ at depths of 200 and $500 \mathrm{~m}$ (Fig. 1c-d). There are some prominent areas of alkalinization $\left(140^{\circ}-175^{\circ} \mathrm{E}, 38^{\circ}-50^{\circ} \mathrm{N}\right)$ in the northwestern Japan Sea and northern subarctic region off the northeast coasts of Hokkaido and Kuril Islands (Fig. 1c-d).

Vertical sections of $\mathrm{pH}_{\text {in situ }}$ along $165^{\circ} \mathrm{E}$ (Fig. 1e) reveal that these patterns of acidification and alkalinization extend vertically, as well as horizontally, with rates of -0.008 to $0.004 \mathrm{yr}^{-1}$. Ocean acidification is occurring at rate of $\leq 0.002 \mathrm{yr}^{-1}$ at the surface, and strong acidification is occurring in the subtropical region south of $25^{\circ} \mathrm{N}$ at depths of $200-800 \mathrm{~m}$. 


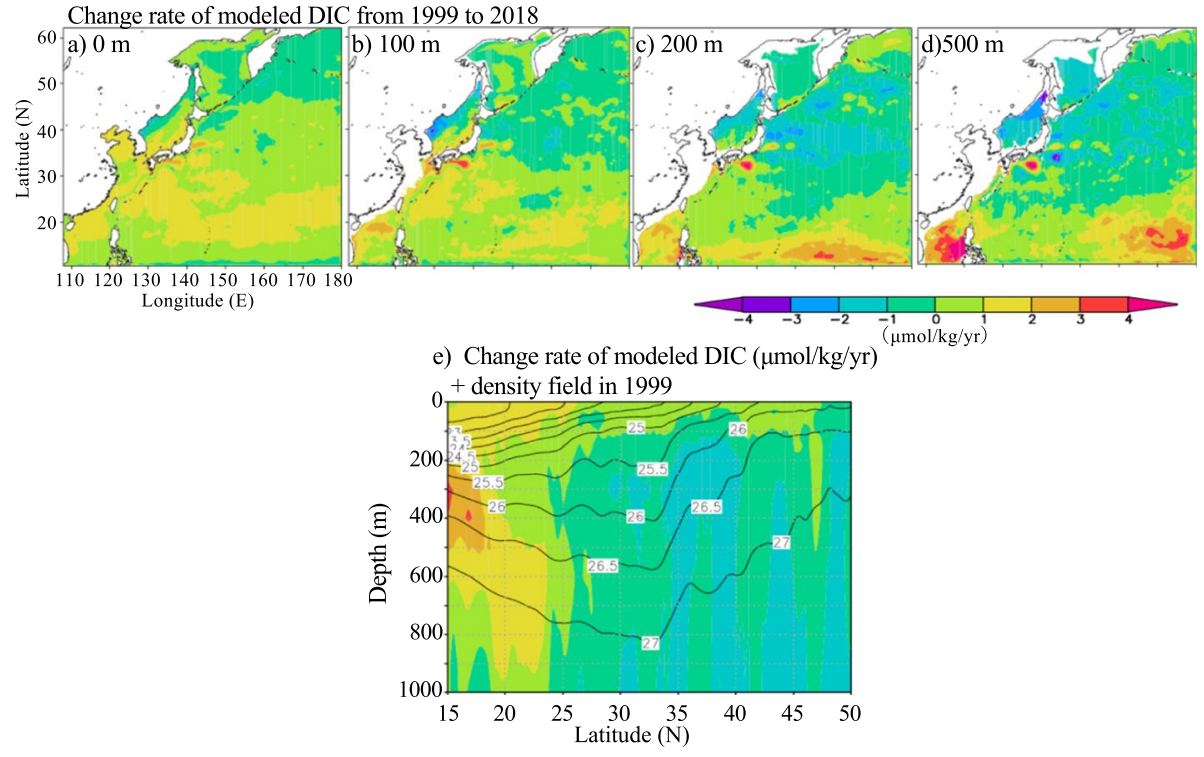

Fig. 2 Same as for Fig. 1 but for modeled DIC. Density contours in (e) are for 1999

Alkalinization is occurring in the area north of $25^{\circ} \mathrm{N}$ at depths below $100 \mathrm{~m}$, especially in the subarctic region (Fig. 1e). Strong acidification or alkalinization is occurring below $200-\mathrm{m}$ depth. Areas of enhanced acidification and alkalinization are found vertically in the regions from $15^{\circ}-25^{\circ} \mathrm{N}$ to $40^{\circ}-45^{\circ} \mathrm{N}$, respectively (Fig. 1e). Although not shown here, the other ocean acidification indices $\left(\mathrm{pH}_{25}\right.$ and $\left.\Omega_{\text {arg }}\right)$ also exhibit similar patterns of acidification and alkalinization as the $\mathrm{pH}_{\mathrm{i} n \text { situ }}$ values (Fig. 1).

\subsection{Comparison between the observational DIC data and model results}

A primary controlling factor on ocean acidification indices is DIC (Ishizu et al. 2019). Therefore, we also show the rate of change of the modeled DIC (Fig. 2). The surface ocean exhibits a large-scale increase in DIC (Fig. 2a), but the DIC changes are not spatially uniform (Fig. 2a-b). The patterns are similar to those of the ocean acidification indices shown in Fig. 1, which indicates that the DIC increase and decrease reflect the pattern of ocean acidification and/or alkalinization.

In our study region, we have obtained DIC measurements along $165^{\circ} \mathrm{E}$. Although the DIC observations exhibit seasonal, interannual, and bi-decadal variability due to temporal variations in the collection of the DIC measurements (Cook et al. 1997; Biondi et al. 2001), the observational DIC data (Fig. 3a-f) show increases and/or decreases that are consistent with the simulation results, including: (1) the DIC increase to be more significant with increasing depth in the subtropical region $\left(15^{\circ}-30^{\circ} \mathrm{N}\right)$; (2) the DIC decrease that spreads partially and/or to all depths in the subarctic region $\left(35^{\circ}-48^{\circ} \mathrm{N}\right)$; (3) some of the areas with a DIC increase being in the subarctic region (Fig. 3a, b, d, e); (4) the DIC increase in the subarctic region being located near the surface layer or close to the Kuroshio Extension $\left(35^{\circ}-40^{\circ}\right.$ N; Fig. $\left.3 a-f\right)$. 

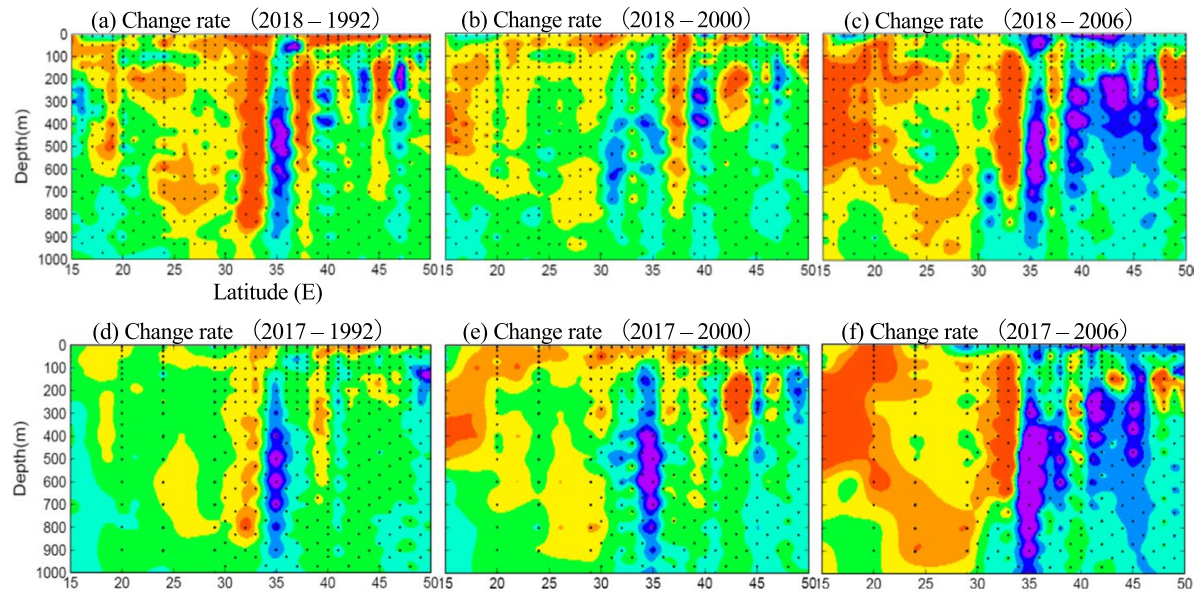

(e) Change rate $(2017-2000)$ (f) Change rate $(2017-2006)$
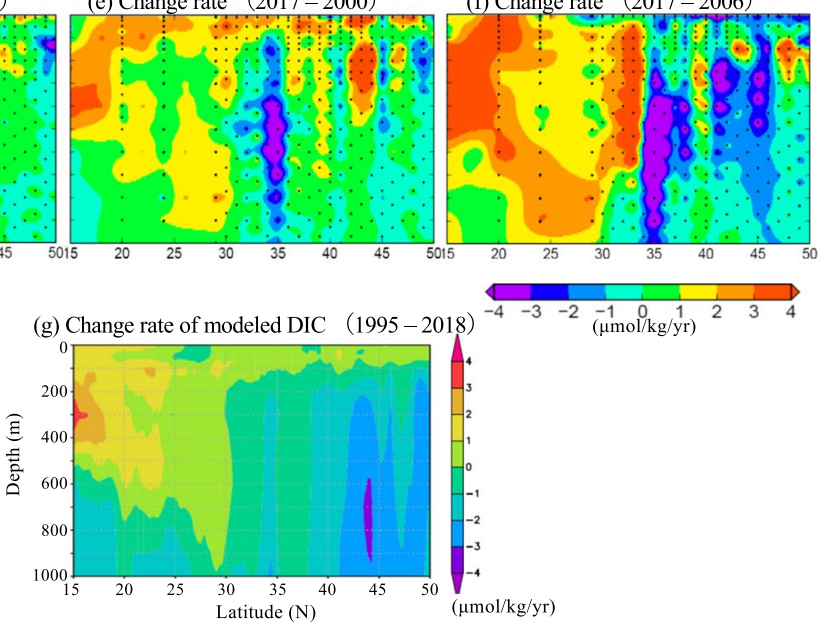

Fig. 3 Vertical sections of the rate of observed DIC change from (a-c) 2018 and (d-f) 2017 to 1992, 2000, 2006, and 2011 along $165^{\circ}$ E. (g) Same as for Fig. 2e, but for the change in the rate of modeled DIC from 1995 to 2018

The vertical distributions of the simulated DIC and observational DIC changes (Figs. 2, 3a-f) show that the area of DIC decrease below the subsurface is smaller in the model than in the observations. The vertical section of the DIC differences between 1995 and 2018 may include effects from the spin-up process (Fig. 3g). However, the agreement between the DIC changes obtained from the model and observations is better for 1995-2018 than 1999-2018 (Figs. 2e and 3).

\section{Discussion}

\subsection{Comparison with observational data}

Midorikawa et al. (2010) found that ocean acidification is occurring in the surface waters of the subtropical region, and estimated $\mathrm{pH}_{25}$ changes of $0.0013 \pm 0.0005 \mathrm{yr}^{-1}$ for summer and $0.0018 \pm 0.0002 \mathrm{yr}^{-1}$ for winter along $137^{\circ} \mathrm{E}$. Our model estimates that the surface $\mathrm{pH}_{25}$ changes at a rate of $0.0019 \mathrm{yr}^{-1}$ at $30^{\circ} \mathrm{N}$ and $137^{\circ} \mathrm{E}$, which is consistent with the estimate of Midorikawa et al. (2010). In the northern part of our study area, Wakita et al. (2013) estimated that ocean acidification was occurring at a rate of $0.0011 \pm 0.0004 \mathrm{yr}^{-1}$ in the surface mixed layer, and $0.0051 \pm 0.0010 \mathrm{yr}^{-1}$ in the $200-250-\mathrm{m}$ depth range at the 
$\mathrm{K} 2$ station $\left(47^{\circ} \mathrm{N}, 160^{\circ} \mathrm{E}\right)$. However, our simulation results in the North Pacific suggest alkalinization is occurring at depths greater than $100 \mathrm{~m}$, and that even stronger alkalinization is occurring below $100 \mathrm{~m}$ in the northern Northwest Pacific and Japan Sea (Fig. 1). The differences between the observations and modeling studies could be due to the time required to confidently detect (anthropogenic) trends (McKinley et al. 2016; Schlunegger et al. 2019). In general, modeling studies indicate that an 20 -year time-series of carbonchemistry related to sea-surface properties is needed to robustly identify anthropogenic trends (McKinley et al. 2016; Schlunegger et al. 2019).

Several research programs are measuring state variables related to ocean acidification indices. The World Ocean Circulation Experiment (WOCE) includes cruise lines that obtain annual observations from some of these programs (Carter et al. 2017; Ono et al. 2019). The Ocean Carbon and Acidification Data Portal is currently organizing a system for gathering observational data and making it publicly available (https://www.nodc.noaa. gov/oads/stewardship/data_portal.html). The additional data from these programs may provide an improved three-dimensional view of acidification and alkalinization in the global oceans.

\subsection{Air-sea $\mathrm{CO}_{2}$ flux}

The horizontal distribution of annual air-sea $\mathrm{CO}_{2}$ fluxes (Fig. 4) shows that most of the Pacific plays a role in outgassing $\mathrm{CO}_{2}$ to the atmosphere, except for marginal seas (i.e., the Japan and East China seas). The polar frontal area $\left(40^{\circ}-45^{\circ} \mathrm{N}, 140^{\circ}-180^{\circ} \mathrm{E}\right)$ also appears to be undergoing active uptake of $\mathrm{CO}_{2}$. Several historical studies have noted the poor agreement between measured and modeled $\mathrm{pCO}_{2}$ values which is calculated from DIC and ALK (Orr and Epitalon 2015; Valsala and Maksyutov 2010; Ishizu et al. 2019, 2020). In our study region, the calculated oceanic $\mathrm{pCO}_{2}$ value is larger than the climatological value by -70 to $70 \mu \mathrm{atm}$ (Valsala and Maksyutov 2010). The modeled absorption rate in the Kuroshio-Oyashio transition area therefore may be smaller than the observed absorption rate and then the area of the DIC increase in the model tends to be smaller than that suggested by the observational data (Fig. 2).

Fig. 4 Annual mean air-sea $\mathrm{CO}_{2}$ flux of the modeled outputs from 1999 to 2018. Positive and negative values represent $\mathrm{CO}_{2}$ uptake and release, respectively

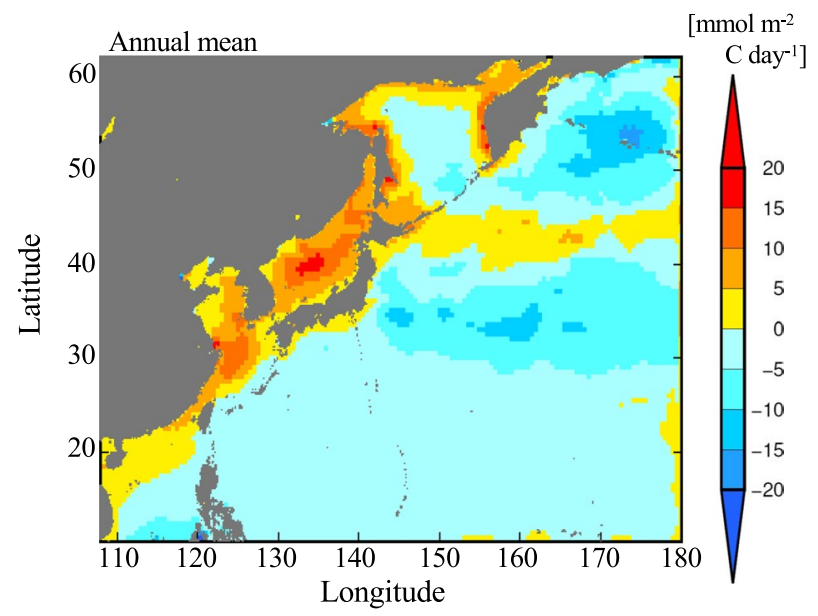


Fig. 5 Time-series of annual air-sea $\mathrm{CO}_{2}$ fluxes of the model outputs from 1999 to 2018 in the subarctic region (blue), Kuroshio Extension (red), and subtropical region (gray). The annual air-sea $\mathrm{CO}_{2}$ flux is divided into the subarctic region $\left(155^{\circ}-175^{\circ} \mathrm{E}\right.$, $\left.40^{\circ}-50^{\circ} \mathrm{N}\right)$, Kuroshio Extension $\left(142^{\circ}-175^{\circ} \mathrm{E}, 30^{\circ}-40^{\circ} \mathrm{N}\right)$, and subtropical region $\left(130^{\circ}-175^{\circ} \mathrm{E}\right.$, $\left.15^{\circ}-30^{\circ} \mathrm{N}\right)$. Positive and negative values represent $\mathrm{CO}_{2}$ uptake and release, respectively

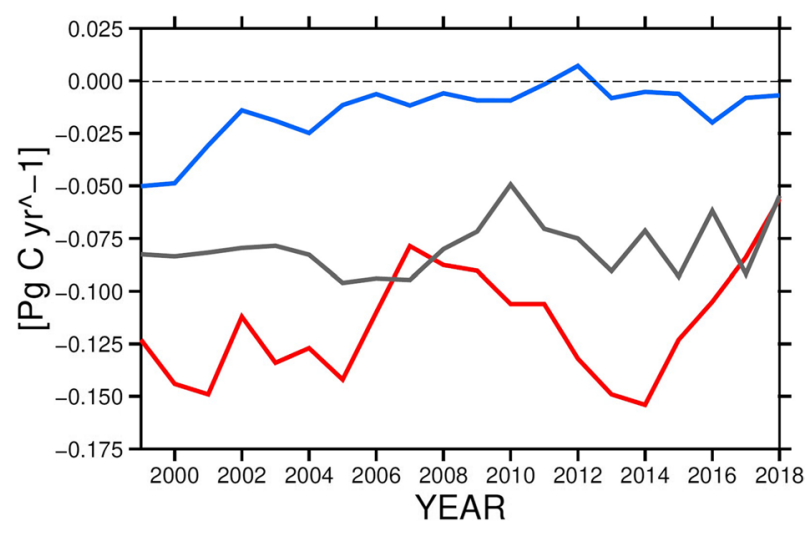

The annual air-sea $\mathrm{CO}_{2}$ flux from the ocean to atmosphere (Fig. 5) gradually decreased from 1999 to 2018 in the subarctic region, Kuroshio Extension, and subtropical region. The statistical regression analyses of the subarctic region, Kuroshio Extension, and subtropical region yielded trends of $0.0015,0.0015$, and $0.0006 \mathrm{Pg} \mathrm{C} \mathrm{yr}^{-1}$, respectively. The p-values for each region were $6.9 \times 10^{-5}, 5.5 \times 10^{-2}$, and $1.4 \times 10^{-1}$, respectively. Since all the regressions are positive, the $\mathrm{CO}_{2}$ release in the subarctic region, Kuroshio Extension, and subtropical region decreases with increasing atmospheric $\mathrm{CO}_{2}$ concentrations. Only the p-values for the Kuroshio Extension and subtropical region are $>0.05$, indicating that the statistical regression in the subarctic region is not reliable. Large variability in the air-sea $\mathrm{CO}_{2}$ fluxes in the Kuroshio Extension (Fig. 5) is likely driven by strong eddy activity.

\subsection{Possible mechanisms of long-term changes in ocean acidification and alkalinization in the Northwest Pacific represented by JCOPE_EC}

We further examined the processes leading to either acidification or alkalinization between the subtropical and subarctic regions of the Northwest Pacific (Figs. 1, 2). To do this, we calculated the mean balances of the DIC variation terms generated by physical and biological processes, as follows (Ishizu et al. 2019):

$$
\frac{\partial[D I C]}{\partial t}=\left[\frac{\partial[D I C]}{\partial t}\right]_{A}+\left[\frac{\partial[D I C]}{\partial t}\right]_{x y \_d i f}+\left[\frac{\partial[D I C]}{\partial t}\right]_{z \_d i f}+\left[\frac{\partial[D I C]}{\partial t}\right]_{B i o}+\left[\frac{\partial[D I C]}{\partial t}\right]_{\text {air }- \text { sea }},
$$

where the subscripts $A, x y \_d i f, z \_d i f$, Bio, and air-sea represent the time derivatives of DIC induced by advection, horizontal diffusion (i.e., horizontal mixing), vertical mixing, biological processes, and air-sea $\mathrm{CO}_{2}$ exchange, respectively (positive air-sea values indicate a transfer of $\mathrm{CO}_{2}$ from air to sea). We refer to these as the "DIC variation terms", and the DIC variations induced by air-sea $\mathrm{CO}_{2}$ exchange were only included for the surface level. The total DIC variation term on the left-hand side of Eq. (2) is the sum of all terms on the right-hand side of the equation. The averaged terms for the period from 1999-2018 were analyzed. The temporally averaged total variation term $\frac{\partial[D I C]}{\partial t}$ (left-hand side of Eq. (2)) is thus not the same as the change rate term (Eq. (1)), which was calculated from the difference between the annual mean for 1999 and 2018.

The horizontal distributions of the DIC variation terms in Eq. (2) are shown in Figs. 6, 7, 8, while Fig. 9 displays the depth-dependent variation in the DIC variation terms 


$$
\begin{aligned}
& \frac{\partial[D I C]}{\partial t}=\left[\frac{\partial[D I C]}{\partial t}\right]_{A}+\left[\frac{\partial[D I C]}{\partial t}\right]_{x y_{-} \text {dif }}+\left[\frac{\partial[D I C]}{\partial t}\right]_{z_{-} \text {dif }}+\left[\frac{\partial[D I C]}{\partial t}\right]_{B i o}+\left[\frac{\partial[D I C]}{\partial t}\right]_{\text {air-sea }} \\
& \Delta \text { DIC Advection Horizontal mixing Vertical mixing Biological processes Air-sea exchange } \\
& \text { (6) (1) (3) (4) (5) }
\end{aligned}
$$
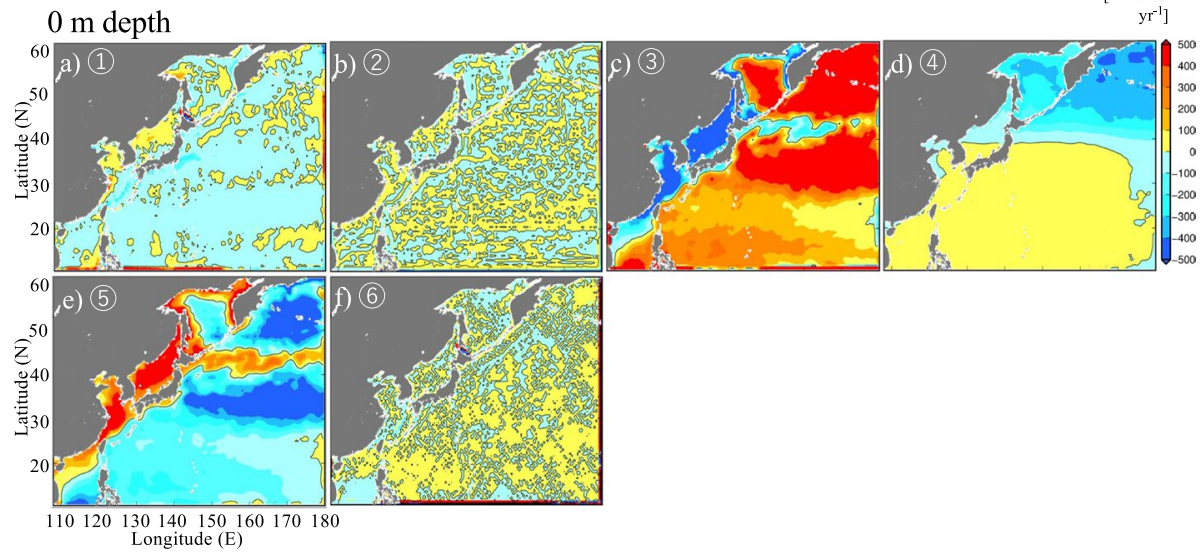

$50 \mathrm{~m}$ depth

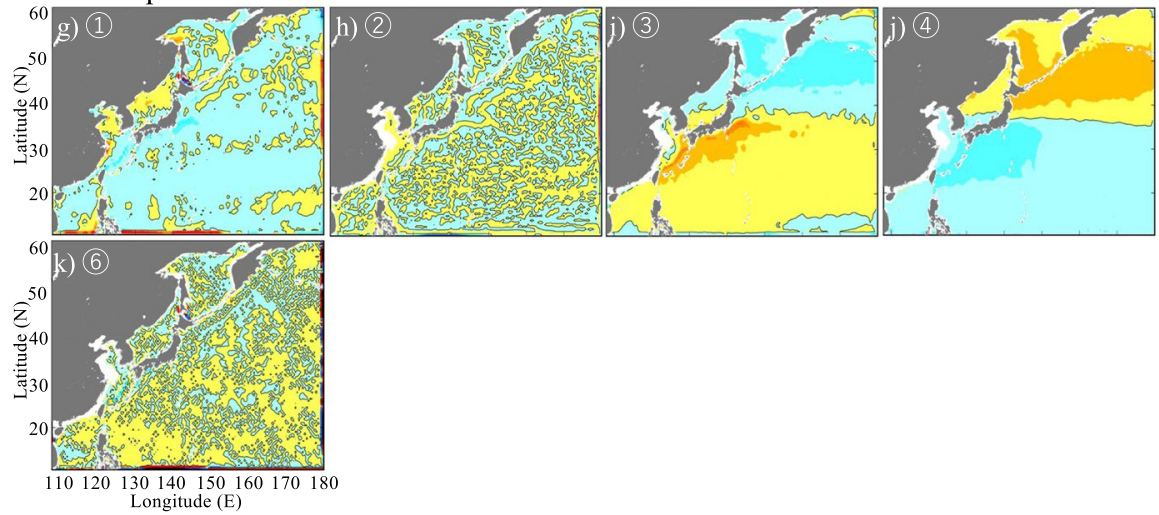

Fig. 6 Horizontal distributions of annual modeled DIC variations generated by (a, g) advection, (b, h) horizontal diffusion, (c, i) vertical mixing, $(\mathbf{e}, \mathbf{j})$ biological processes, and (e) air-sea $\mathrm{CO}_{2}$ exchange, and (f, k) total modeled DIC temporal variations at $(\mathbf{a}-\mathbf{f}) 0 \mathrm{~m}$ and $(\mathbf{g}-\mathbf{k}) 50 \mathrm{~m}$ depths. Positive and negative values represent increases and decreases that each term produces on the modeled DIC variations, respectively. The modeled DIC variation due to air-sea $\mathrm{CO}_{2}$ exchange was only considered in surface waters

along the $165^{\circ} \mathrm{E}$ line at $20^{\circ}, 30^{\circ}, 40^{\circ}$, and $50^{\circ} \mathrm{N}$. The balances at the surface (Fig. $6 \mathrm{a}-\mathrm{f}$ ) indicate that air-sea exchange is generally balanced by vertical mixing (Figs. 6c, e and $9 \mathrm{a}-\mathrm{d})$, and that biological processes drive the DIC increase in the Kuroshio Extension and subtropical region, as well as the DIC decrease in the subarctic region north of $50^{\circ} \mathrm{N}$ (Figs. 6d and 9a-d). This DIC increase in the Kuroshio Extension and subtropical region can be attributed to remineralization, which occurs due to the spreading of detritus originating from zooplankton (not shown). The DIC decrease in the subarctic region is due to 

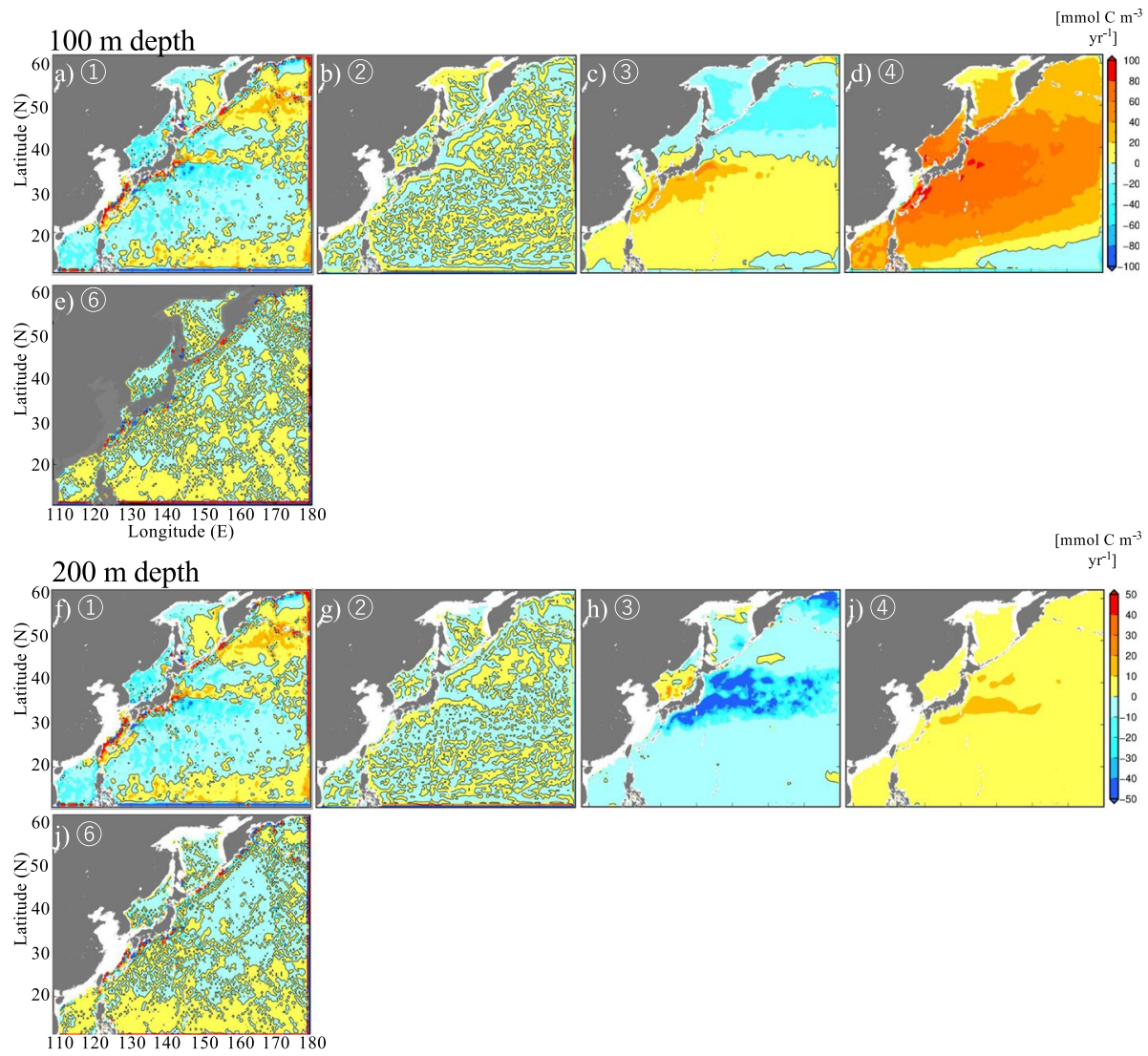

Fig. 7 Same as for Fig. 6, but the horizontal distributions of annual modeled DIC variations generated by $(\mathbf{a}, \mathbf{e})$ advection, $(\mathbf{b}, \mathbf{f})$ horizontal diffusion, $(\mathbf{c}, \mathbf{g})$ vertical mixing, $(\mathbf{e}, \mathbf{h})$ biological processes, and $(\mathbf{d}, \mathbf{i})$ total modeled DIC temporal variations at (a-d) $100 \mathrm{~m}$ and (e-i) $200 \mathrm{~m}$ depths

photosynthesis. The balance of the annual DIC variations terms along the $165^{\circ} \mathrm{E}$ line in the subtropical region and surface region of the Kuroshio Extension (Fig. 9a, b, e) suggests that the DIC supply, which is primarily controlled by vertical mixing, surpasses the DIC release by air-sea exchange. As the depth increases (Figs. 6g-k, 7, 8, and 9e-s), the DIC temporal variations are primarily driven by vertical mixing, biological processes, and/or advection. Vertical mixing transports DIC from deeper to subsurface waters (above $50 \mathrm{~m}$ ) in the subtropical region and Kuroshio Extension (Figs. 6c, j and 9e, f). At 100-m depth, the positive DIC values from the subarctic to subtropical regions (Fig. 7d) indicate production of DIC by remineralization. Such latitudinal differences between the subtropical and subarctic regions due to biological processes (Fig. 7d, i) can be linked to latitudinal differences in the depth of the chlorophyll maximum in the Northwest Pacific (Sauzede et al. 2015; Ishizu et al. 2020). Below $200 \mathrm{~m}$ depth (Figs. 7f-j and 8), biological processes become less important in driving DIC variations. Instead, advection 

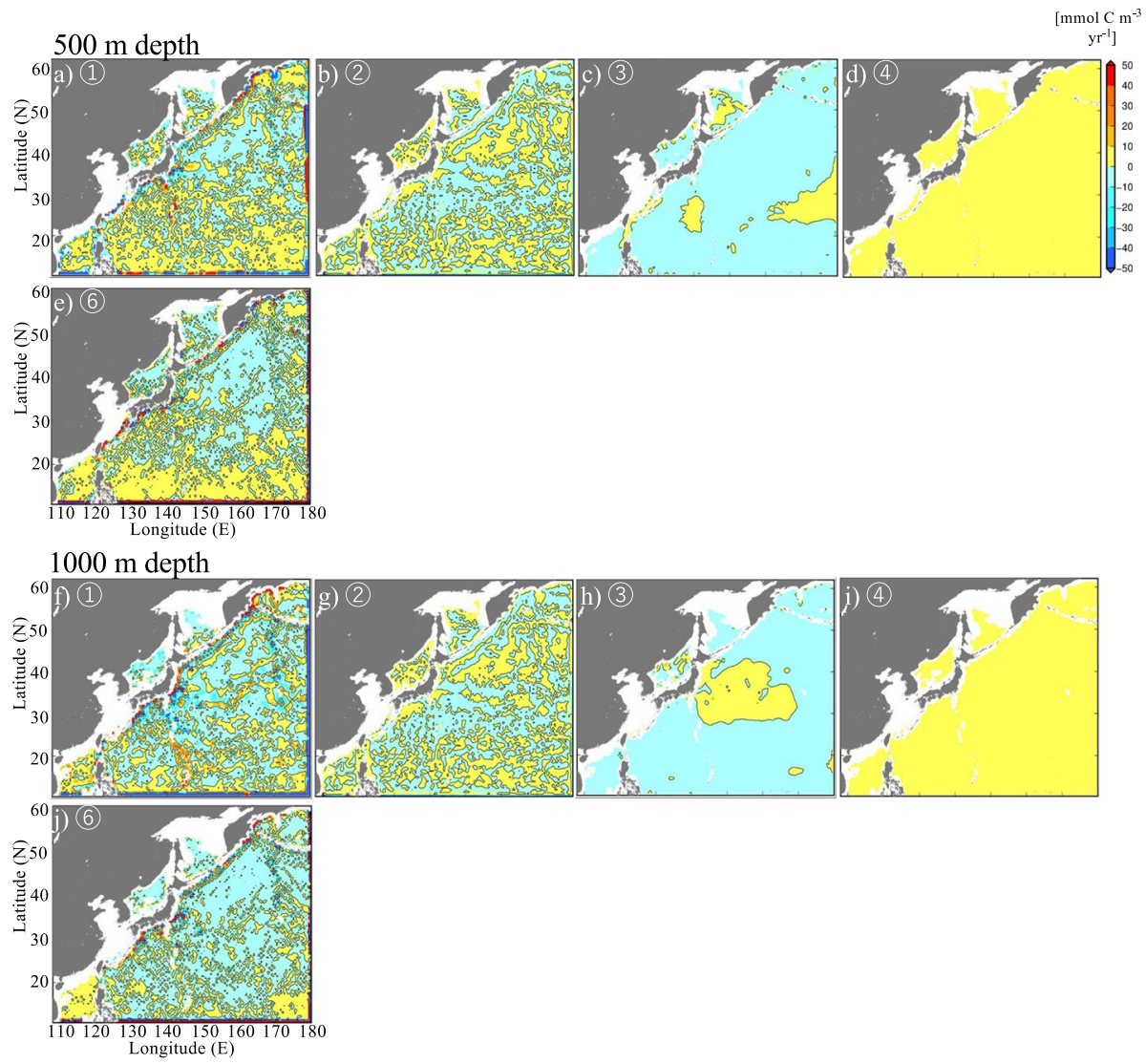

Fig. 8 Same as for Fig. 6, but the horizontal distributions of annual modeled DIC variations generated by $(\mathbf{a}, \mathbf{e})$ advection, $(\mathbf{b}, \mathbf{f})$ horizontal diffusion, $(\mathbf{c}, \mathbf{g})$ vertical mixing, $(\mathbf{e}, \mathbf{h})$ biological processes, and $(\mathbf{d}, \mathbf{i})$ total modeled DIC temporal variations at (a-d) $500 \mathrm{~m}$ and (e-i) $1000 \mathrm{~m}$ depths

is largely responsible for DIC variations via vertical mixing (Figs. 7f, h, j and 9m-s). Horizontal mixing does not appear to have an important role in driving lateral or depthdependent DIC variations across the study area, especially in the surface and subsurface (Figs. 7, 8).

DIC observations (Fig. 3) suggest that ocean acidification in the subtropical region at the surface, as well as in deeper layers, has progressed more rapidly than in the subarctic region. Results from the simulation suggest that vertical mixing balances the emission of DIC at the surface, despite $\mathrm{CO}_{2}$ release to the atmosphere. However, in the subtropical region, the positive DIC values due to remineralization also occur at the surface (Fig. 9a-b), because the photosynthesis zone occurs to depths of 150-200 m (Ishizu et al. 2019). Below 100-m depth, the model results suggest that the supply from DIC transport due to vertical mixing and/or advection in the subarctic region below 
$\triangle \mathrm{DIC}$ Advection Horizontal mixing Vertical mixing Biological processes Air-sea exchange

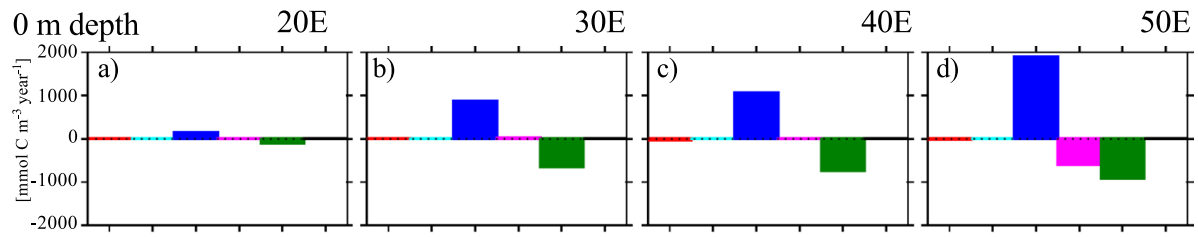

$50 \mathrm{~m}$ depth
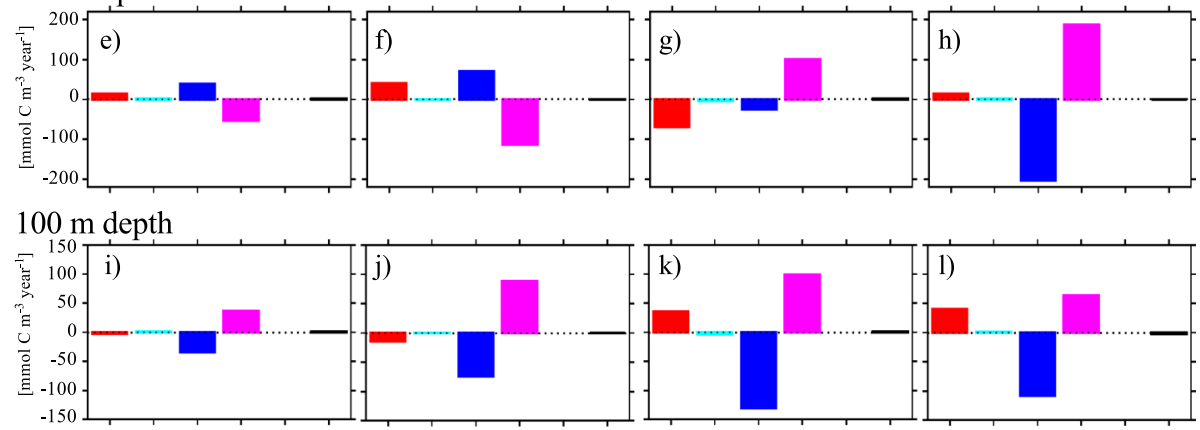

$200 \mathrm{~m}$ depth

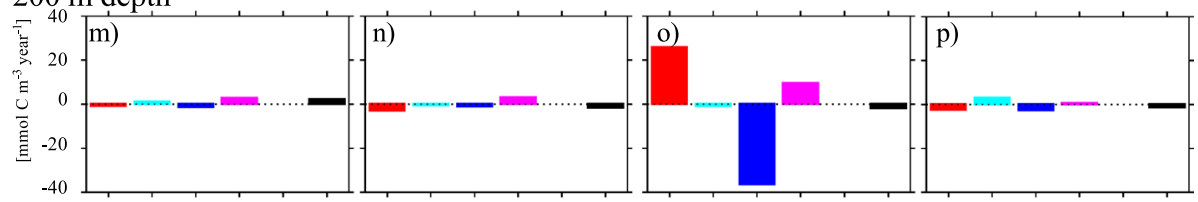

$500 \mathrm{~m}$ depth
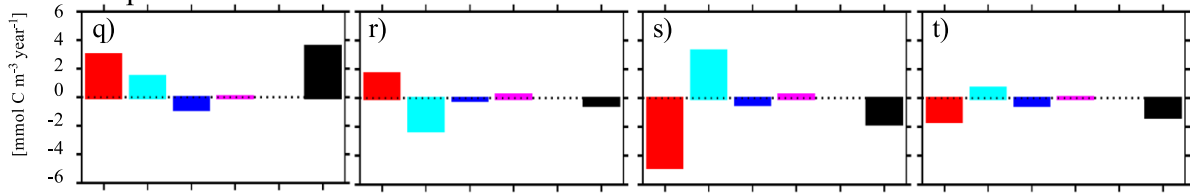

$1000 \mathrm{~m}$ depth
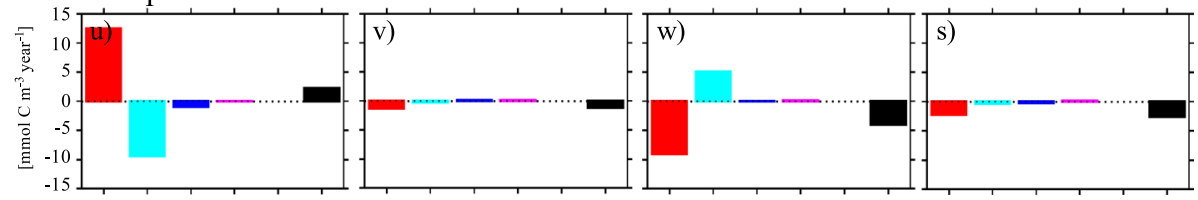

Fig. 9 Histograms of annual modeled DIC variations at $165^{\circ} \mathrm{E}$. Partitioning of DIC variations into contributions from advection, horizontal diffusion, vertical mixing, biological processes, and air-sea $\mathrm{CO}_{2}$ exchange, and total modeled DIC temporal variations, at (a-d) $0 \mathrm{~m},(\mathbf{e}-\mathbf{h}) 50 \mathrm{~m},(\mathbf{i}-\mathbf{l}) 100 \mathrm{~m},(\mathbf{m}-\mathbf{p}) 200 \mathrm{~m},(\mathbf{q}-\mathbf{t})$ $500 \mathrm{~m}$, and (u-s) $1000 \mathrm{~m}$ depths at the (a, e, i, m, q, u) $20^{\circ} \mathrm{E},(\mathrm{b}, \mathrm{f}, \mathrm{j}, \mathrm{n}, \mathrm{r}, \mathrm{v}) 30^{\circ} \mathrm{E},(\mathrm{c}, \mathrm{g}, \mathrm{k}, \mathrm{o}, \mathrm{s}, \mathrm{w}) 40^{\circ} \mathrm{E}$, and $(\mathrm{d}, \mathrm{h}, 1, \mathrm{t}, \mathrm{s}) 50^{\circ} \mathrm{E}$. The annual mean values were calculated within five grids $(22.0-45.5 \mathrm{~km})$ of the target region. The colored bars have the same colors as the processes in shown in Figs. 6, 7 and 8

$100 \mathrm{~m}$ is less than that of the upper layers (Figs. 6, 7, 8 and $9 \mathrm{k}-1, \mathrm{n}-\mathrm{p}, \mathrm{r}-\mathrm{t}, \mathrm{v}-\mathrm{s}$ ). This process is responsible for the DIC decrease in the subarctic region (Figs. 2b-d and 3 ), and likely leads to the alkalinization below the subsurface layers (Fig. 1b-e). DIC 
Fig. 10 Schematic illustration of the formation of the main water masses and near-surface currents in the Northwest Pacific. Red, green, and blue ellipses denote the formation regions of the STMW, S-CMW, D-CMW, OSMW, and DWS, respectively. Colored arrows show the current paths of the Kuroshio, OSMW, and DSW. Colored dashed arrows show the spreading of the water masses after subduction. STMW = Subtropical Mode Water; S-CMW = Shallower Central Mode Water; D-CMW = Deeper Central Mode Water; OSMW= Ohotsk Sea Mode Water; DSW = Dense Shelf Water; NPIW = North Pacific Intermediate Water

Fig. 11 A schematic of the acidification and alkalinization mechanisms across different latitudes in the Northwest Pacific, which were obtained from the simulation results. Red and blue colored areas represent acidification and alkalinization, respectively. The green colored area shows the phytoplankton zone, where modeled DIC is consumed in the surface and subsurface layers. The blue arrows indicate the movement of DIC and carbon input due to air-sea $\mathrm{CO}_{2}$ exchange

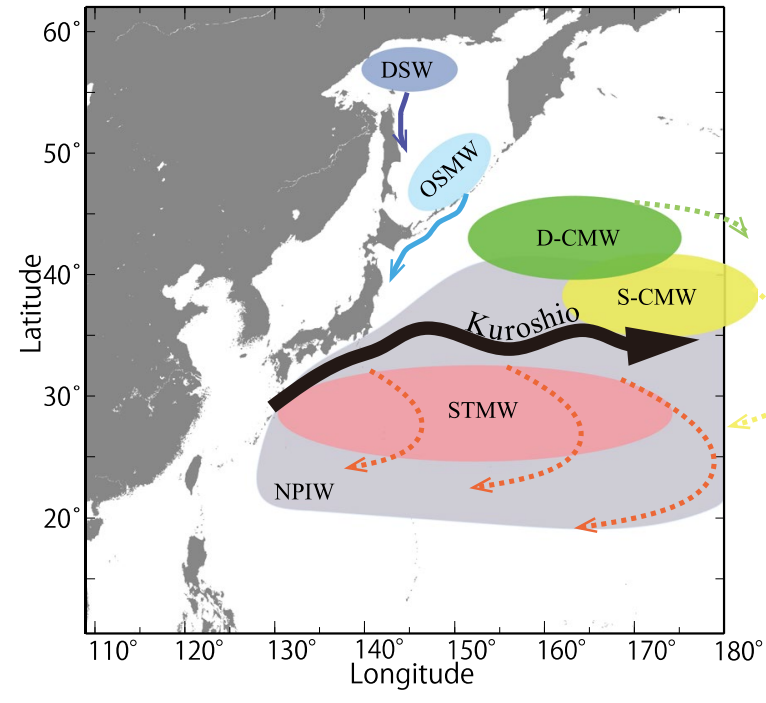

Air-Sea $\mathrm{CO}_{2}$ exchange

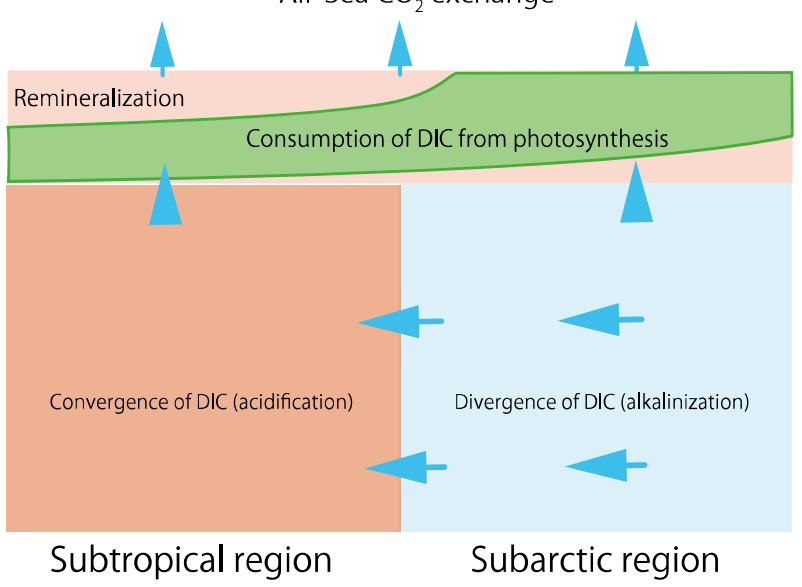

is transported to the Kuroshio Extension and subtropical region below 200-m depths and is involved in the formation and transport of mode waters in the Northwest Pacific (Figs. 1 and 10), such as the Central Mode Water (S-CMW, 26.0-26.4 $\sigma_{\theta}$; D-CMW, 26.4-26.7 $\sigma_{\theta}$; Suga et al. 1997), Subtropical Mode Water (STMW, 25.2-25.8 $\sigma_{\theta}$; Masuzawa 1969), and NPIW (26.7-27.0 $\sigma_{\theta}$; Sverdrup et al. 1942; Talley 1993; Yasuda 1997, 2004; Fujii et al. 2013), which occur in the 200-600-m depth range (Figs. 2c-e, 3). The density contours (Fig. 2e) imply that the DIC in the subarctic region is transported to the subtropical region by the water masses of mode waters. Figure 11 illustrates the mechanisms of acidification and alkalinization in a vertical section in the Northwest Pacific. 


\section{Conclusions}

A biogeochemical model with an operational ocean product was used to examine longterm three-dimensional variations in ocean acidification indices and state variables related to ocean acidification from 1993 to 2018. The model results reveal an increase in DIC and ocean acidification over most of the surface layer. The Northwest Pacific became less of a $\mathrm{CO}_{2}$ source to the atmosphere from 1999 to 2018. Our results reveal differences between the subtropical and subarctic regions, particularly at increasing depths. Ocean acidification is occurring in the subtropical region, while alkalinization is occurring in the subarctic region. The model indicates that ocean acidification represented by our model is strongly controlled by the physical transport of DIC by ocean circulation and biological activity. Historical DIC observations in the Northwest Pacific show similar patterns across the Kuroshio Extension region. At depths below $100 \mathrm{~m}$, we identified ocean acidification in the subtropical region and alkalinization in the subarctic region, where advection, horizontal transport, and vertical diffusion are important processes. Biological processes also modulate the physical processes above depths of $150-200 \mathrm{~m}$ in the subtropical region.

Although our model experiment does not distinguish between DIC changes due to ocean circulation and those due to increased sequestration of atmospheric $\mathrm{CO}_{2}$ as a consequence of increasing atmospheric $\mathrm{CO}_{2}$, our model does allow us to examine the mechanisms responsible for the stronger ocean acidification in the subtropical gyre south of the Kuroshio Extension relative to the subarctic region. $\mathrm{CO}_{2}$ may be sequestered by the Kuroshio Extension in winter by subduction processes (not shown), and the injected $\mathrm{CO}_{2}$ in the subsurface and deeper layers may gradually reach the surface, with possibly more rapid transport to the surface in the subtropical region. Our simulation results show a sustained amplification of DIC and acidification in the subtropical region and along the coastal area south of $35^{\circ} \mathrm{N}$ in the Northwest Pacific, and it is uncertain if this trend will persist into the future. The possible sustained amplification of spatially heterogeneous acidification rates has important consequences for marine life and mitigation strategies.

\section{Appendix Spin-up processes}

The averaged DIC time-series in the subarctic region, Kuroshio Extension, and subtropical region from 1993 to 2008 were calculated in the surface $(0-100 \mathrm{~m})$, subsurface $(100-500 \mathrm{~m})$, middle $(500-1000 \mathrm{~m})$, and deeper $(1000-2000 \mathrm{~m})$ layers. The DIC time-series in the surface layer (Fig. 12a) varies more than those in the deeper layers (Fig. 12b-d). In the subsurface layer (Fig. 12b), DIC values decrease in the subarctic region, but increase in the Kuroshio Extension and subtropical region. In the layers deeper than $500 \mathrm{~m}$ (Fig. 12c-d), a widespread decrease in DIC is observed. The DIC changes gradually with time and its fluctuations become smaller, except in surface waters (Fig. 12a). This DIC time-series from 1993 to 2018 was used to define the spin-up process for the model output prior to 1999.

Figures 13 and 14 
Fig. 12 Time-series of annual modeled DIC variations from 1993 to 2018 in each layer in the subtropical region (black), Kuroshio Extension (green), and subtropical region (red). (a-d) The time-series in the surface (0-100 m depth), subsurface (100-500 m depth), middle (500-1000 m depth), and deeper layers (1000-2000 m depth), respectively
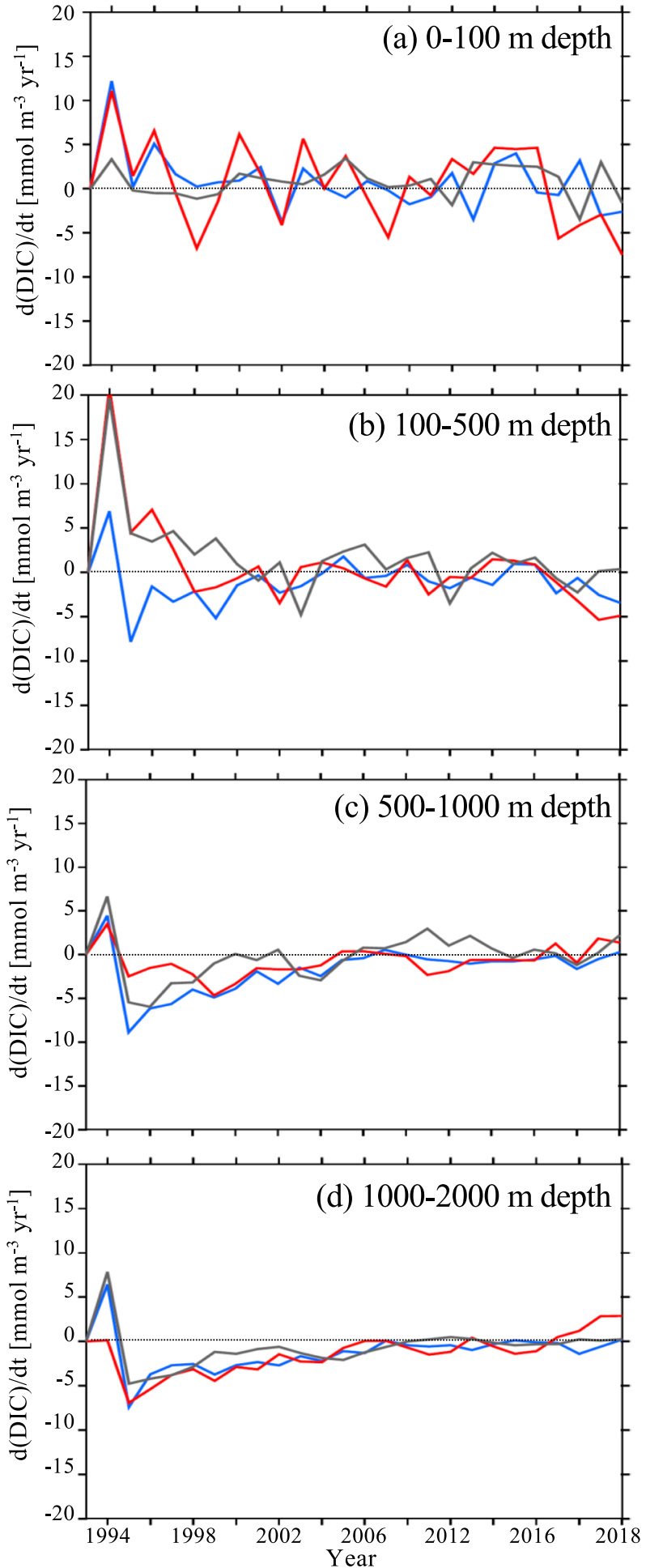

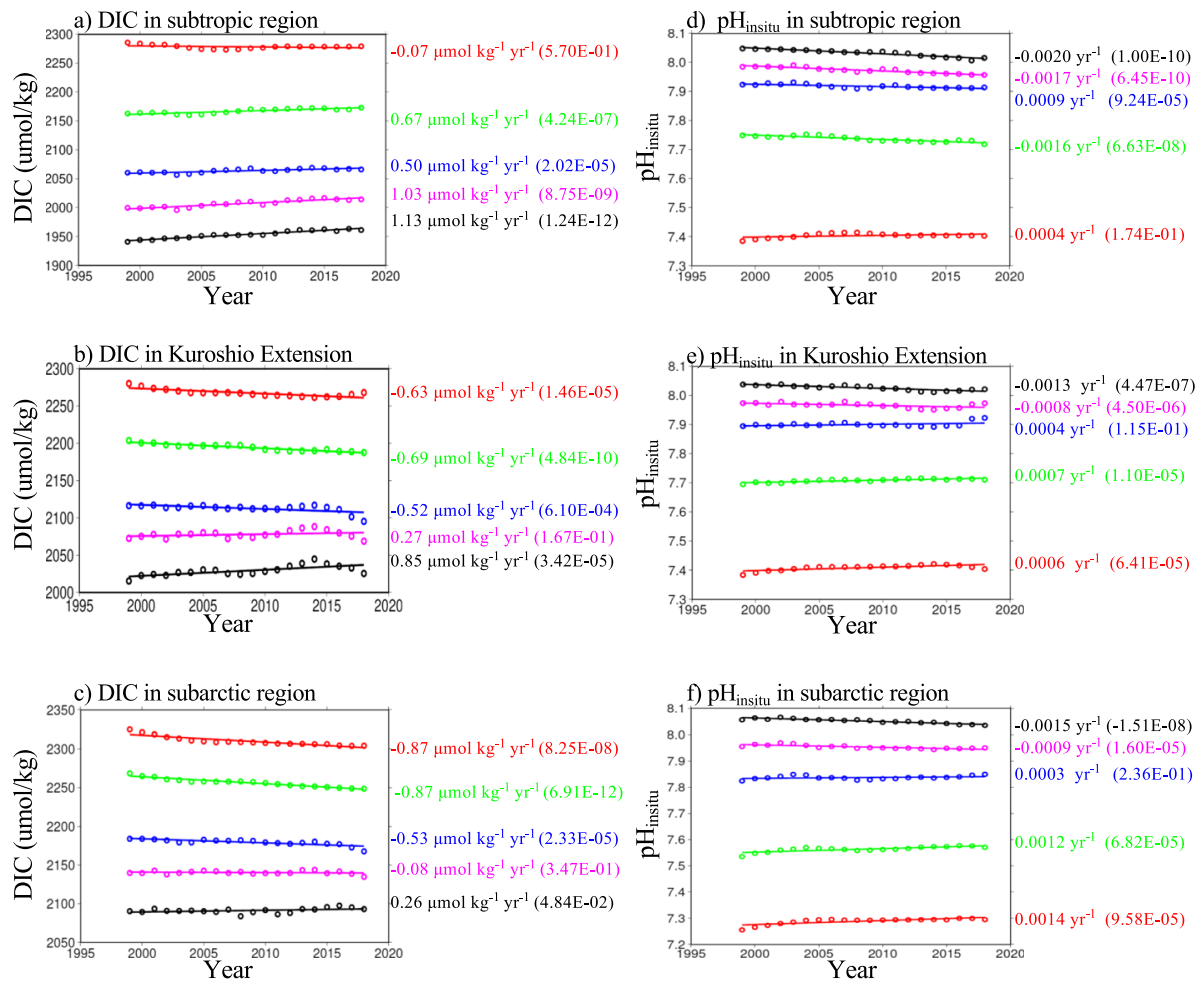

Fig. 13 Annual mean values and linear regression trends in (a-c) modeled DIC and (d-f) modeled $\mathrm{pH}_{\text {in situ }}$ (d-f) in the subtropical region, Kuroshio Extension, and subarctic region, respectively (Table 1). Red, green, blue, purple, and black colors are data for 0, 100, 200, 500, and $1000 \mathrm{~m}$, respectively. Regression coefficients and $\mathrm{p}$-values are given in parentheses on the right side of the figure 

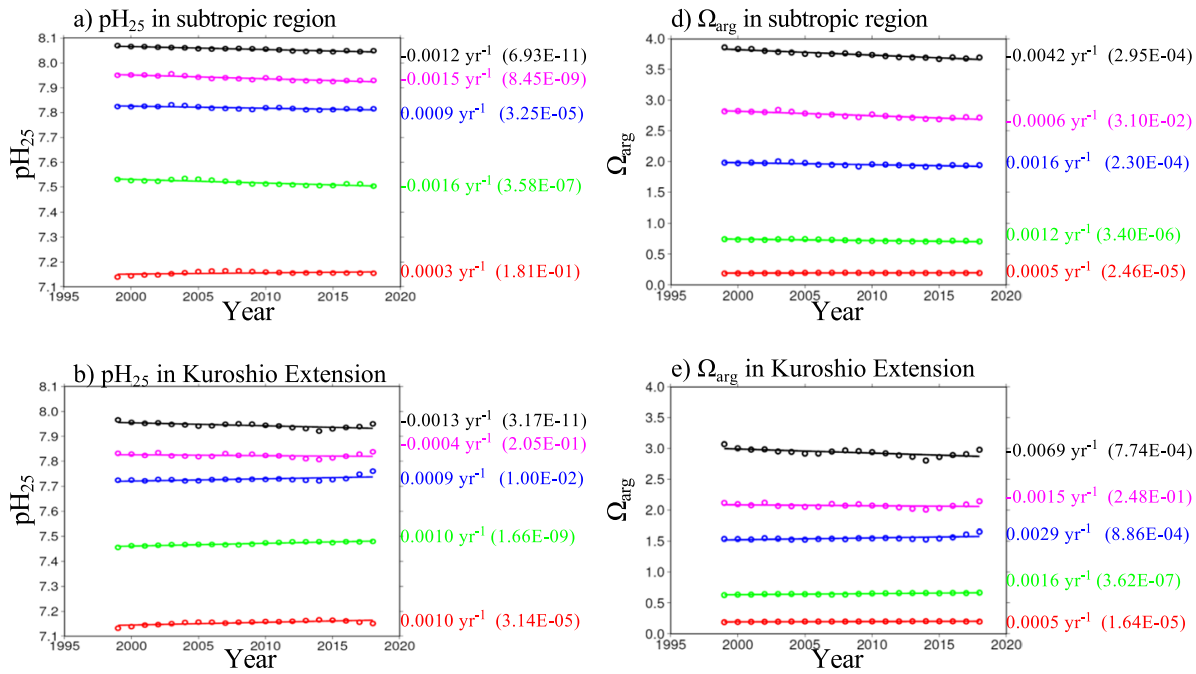

c) $\mathrm{pH}_{25}$ in subarctic region
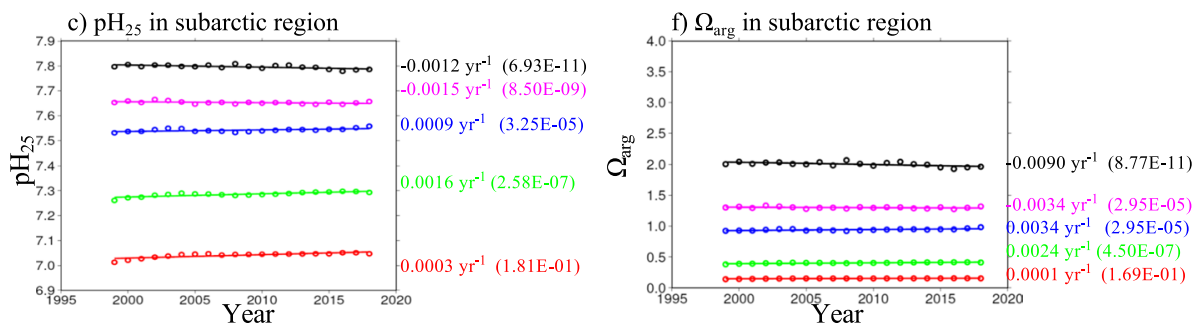

Fig. 14 Same as for Appendix Fig. 13, but for modeled $\mathrm{pH}_{25}$ and $\Omega_{\text {arg }}$

Acknowledgements We acknowledge support from the Sasakawa Peace Foundation of the Ocean Policy Research Institute (OPRI-SPF). This study is part of the Japan Coastal Ocean Predictability Experiment (JCOPE) supported by the Japan Agency for Marine-Earth Science and Technology (JAMSTEC).

Open Access This article is licensed under a Creative Commons Attribution 4.0 International License, which permits use, sharing, adaptation, distribution and reproduction in any medium or format, as long as you give appropriate credit to the original author(s) and the source, provide a link to the Creative Commons licence, and indicate if changes were made. The images or other third party material in this article are included in the article's Creative Commons licence, unless indicated otherwise in a credit line to the material. If material is not included in the article's Creative Commons licence and your intended use is not permitted by statutory regulation or exceeds the permitted use, you will need to obtain permission directly from the copyright holder. To view a copy of this licence, visit http://creativecommons.org/licenses/by/4.0/.

\section{References}

Bates NR (2007) Interannual variability of the ocean $\mathrm{CO}_{2}$ sink in the subtropical gyre of the North Atlantic Ocean over the last 2 decades. J Geophys Res 112:C09013. https://doi.org/10.1029/2006JC003759

Bates NR, Astor YM, Church MJ, Currie K, Dore JE, Gonzalez-Davila M, Lorenzoni L, Muller-Karger F, Olafsson J, Santana-Casiano JM (2014) A time-series view of changing surface ocean chemistry due to ocean uptake of anthoropogenic $\mathrm{CO}_{2}$ and ocean acidification. Oceanography 27(1):126-141. https:// doi.org/10.5670/oceanog.2014.16.2014 
Biondi F, Gershunov A, Cayan RD (2001) North Pacific decadal climate variability since 1661. J Clim 14:5-10

Carter BR, Feely AR, Mecking S, Cross JN, Macdonald MA, Siedlecki AS, Talley DL, Sabine LC, Millero JF, Swift HJ, Dickson GA, Rodgers BK (2017) Two decades of Pacific anthropogenic carbon storage and ocean acidification along global ocean ship-based hydrographic investigations program sections P16 and P02. Glob Biogeochem Cycles 31:306-327. https://doi.org/10.1002/2016GB005485

Chang YL, Miyazawa Y, Guo X (2015) Effects of the STCC eddies on the Kuroshio based on the 20-year JCOPE2 reanalysis results. Prog Oceanogr 135:64-76. https://doi.org/10.1016/j.pocean.2015.04.006

Chen CTA, Lui H-K, Hsieh C-H, Yanagi T, Kosugi N, Ishii M, Gong G-C (2017) Deep oceans may acidify faster than anticipated due to global warming. Nat Commun:890-895.https://doi.org/10.1038/ s41558-017-0003-y

Cook ER, Meko MD, Stockton WC (1997) A new assessment of possible solar and lunar forcing of bidecadal drought rhythm in the western United States. J Clim 10:1343-1356

Dore JE, Lukus R, Sadler DW, Church MJ, Karl DM (2009) Physical and biogeochemical modulation of ocean acidification in the central North Pacific. Proc Natl Acad Sci 106:12235-12240

Fujii Y, Nakano T, Usui N, Matsumoto S, Tsujino H, Kamachi M (2013) Pathways of the North Pacific Intermediate Water identified through the tangent linear and adjoint models of an ocean general circulation model. J Geophys Res Oceans 118:2035-2051. https://doi.org/10.1002/jgrc.20094

Gonzalez-Davila M, Santana-Casiano JM, Gonzalez-Davila EF (2007) Interannual variability of the upper ocean carbon cycle in the northeast Atlantic Ocean. Geophys Res Lett 34:L07608. https://doi.org/10. 1029/2006GL028145

Intergovernmental Panel on Climate Change (IPCC) (2013) Climate Change 2013: The Physical Science Basis Contribution of Working Group I to the Fifth Assessment Report of the Intergovernmental Panel on Climate Change. In: Stocker TF, Qin D, G-K Plattner, Tignor MMB, Allen SK, Boschung J, Nauels A, Zia Y, Bex V, Midgley PM (eds) Cambridge University Press, Cambridge and New York, pp $1-1535$

Ishii M, Rodgers BK, Inoue YH, Toyama K, Sasano D, Kosugi N, Enyo K, Nakano T, Iudicone D, Blanke B, Aumount O, Feely AR (2020) Ocean acidification from below in the tropical Pacific. Biogeochem Cycles 34:e2019GB006368. https://doi.org/10.1029/2019GB006368

Ishizu M, Miyazawa Y, Tsunoda T, Guo X (2019) Development of a biogeochemical and carbon model related to ocean acidification indices with an operational ocean model product in the North Western Pacific. Sustainability 11:2677. https://doi.org/10.3390/su11092677

Ishizu M, Miyazawa Y, Guo X, Tsunoda T (2020) Seasonal variability in the inorganic ocean carbon cycle in the Northwest Pacific evaluated using a biogeochemical and carbon model coupled with an operational ocean model. Clim Chang:1-26. https://doi.org/10.1007/s10584-020-02779-2

Masuzawa J (1969) Subtropical Mode Water. Deep-Sea Res 16:463-472

McKinley A, Galen Pilcher J. D, Fay RA, Lindsay K, Long CM, Lovenduski SN (2016) Timescales for detection of trends in the ocean carbon sink. Nature 530:469-472. https://doi.org/10.1038/nature16958

Mellor GL (2001) An equation of state for numerical models of oceans and estuaries. J Atmos Ocean Technol 8:609-611

Midorikawa T, Ishii M, Saito S, Sasano D, Kosugi N, Motoi T, Kamiya H, Nakadate A, Nemoto K, Inoue H (2010) Decreasing pH trend estimated from 25-yr time series of carbonate parameters in the western North Pacific. Tellus 62B:649-659

Miyama T, Minobe S, Goto H (2021) Marine heatwave of sea surface temperature of the Oyashio region in the summer in 2010-2016. Front Mar Sci 7:576240. https://doi.org/10.3389/fmars.2020.576240

Miyazawa Y, Zhang R, Guo X, Tamura H, Ambe D, Lee JS, Yoshinari H, Setou T (2009) Water mass variability in the western north Pacific detected in a 15-year eddy resolving ocean reanalysis. J Oceanogr 65:737-756

Miyazawa Y, Varlamov MS, Miyama T, Guo X, Hihara T, Kiyomatsu K, Kachi M, Kurihara Y, Murakami H (2017) Assimilation of high-resolution sea surface temperature data into an operational nowcast/ forecast system around Japan using a multi-scale three-dimensional variational scheme. Ocean Dyn $67: 713-728$

Miyazawa Y, Kuwano-Yoshida A, Doi T, Nishikawa H, Narazaki T, Fukuoka T, Sato K (2019) Temperature profiling measurements by sea turtles improve ocean state estimation in the Kuroshio-Oyashio Confluence region. Ocean Dyn 69:267-282

Olafsson J, Olafsdottir SR, Benoit-Cattin A, Danielsen M, Arnarson TS, Takahashi T (2009) Rate of Iceland Sea acidification from time series measurements. Biogeosciences 6(2):661-2, 668. https://doi.org/10. 5194/bg-6-2661-2009 
Ono H, Kosugi N, Toyama K, Tsujino H, Kojima A, Enyo K, IidaNakano YT, Ishii M (2019) Acceleration of ocean acidification in the western North Pacific. Geophys Res Lett 46:13161-13169. https://doi.org/ 10.1029/2019GL085121

Orr CJ, Epitalon MJ (2015) Improved routines to model the ocean carbonate system: mocsy 2.0. Geosci Model Dev 8:485-499

Orr JC, Najjar R, Sabine CL, Joos F (1999) Abiodic-HOWTO; Internal OCMIP Report; LSCE/CEA Scalay: Gif-sur-Yvette, France; 25 p

Saeyanto E, Guo X, Ono J, Miyazawa Y (2014) Interannual variations of Kuroshio transport in the East China Sea and its relation to the Pacific decadal oscillation and mesoscale eddies. J Geophys Res Oceans 119:3595-3616. https://doi.org/10.1002/2013JC009529

Sauzede R, Lavigne H, Claustre H, Schmechtig C, Ortenzio DF, Guinet C, Pesant S (2015) Vertical distribution of chlorophyll a concentration and phytoplankton community composition from in situ flurorescence profiles: a first database for the global ocean. Earth Syst Sci Data 2015(7):261-273. https://doi.org/10.5194/essd-7-261-2015

Schlunegger S, Rodgers BK, Sarmiento LJ, Frolicher LT, Dunne PJ, Ishii M, Slater R (2019) Emergence of anthropogenic signals in the ocean carbon cycle. Nat Clim Chang 9:719-725. https://doi.org/10. 1038/s41558-019-0553-2

Suga T, Takai Y, Hanawa K (1997) The subtropical mode water circulation in the North Pacific. J Phys Oceanogr 25:958-970

Sverdrup H, Johnson WM, Flemming HR (1942) The Oceans. Their Physics. Chemistry and Biology. Prentice-Hall, 1087pp

Takahashi T, Sutherland CS, Sweeney C, Poisson A, Metzl N, Tilbrook B, Bates N, Wanninkhof R, Feely AR, Sabin C, Olafsson J, Nojiri Y (2002) Global sea-air $\mathrm{CO}_{2}$ flux based on climatological surface ocean $\mathrm{pCO}_{2}$, and seasonal biological and temperature effects. Deep-Sea Res II 49(49):1601-1622

Takahashi T, Sutherland CS, Wanninkhof R, Sweeney C, Feely AR, Chipman WD, Hales B, Friedrich G, Chaves F, Sbaine C, Watson A, Bakker CED, Schuster U, Metzl N, Yoshikawa-Inoue H, Ishii M, Midorikawa T, Nojiri Y, Kortzinger A, Steinhoff T, Hoppema M, Olafsson J, Arnarson ST, Tilbrook B, Johannessen T, Olsen A, Bellerby R, Wong CS, Delille B, Bates NR, de Baar JWH (2009) Climatological mean and decadal change in surface ocean $\mathrm{pCO}_{2}$ and net sea-air $\mathrm{CO}_{2}$ flux over the global oceans. Deep-Sea Res II 56(56):554-577

Talley LD (1993) Distribution and formation of North Pacific Intermediate Water. J Phys Oceanogr 23:517-537. https://doi.org/10.1175/1520-0485

Toyama K, Rodger BK, Blanke B, Iudicone D, Ishii M, Aumont O, Sarmiento LJ (2017) Large Reemergence of anthropogenic carbon into the ocean's surface mixed layer sustained by the ocean's overturning circulation. J Clim 30:8615-8631. https://doi.org/10.1175/JCLI-D-16-0725.1

Valsala V, Maksyutov S (2010) Simulation and assimilation of global ocean $\mathrm{pCO}_{2}$ and air-sea $\mathrm{CO}_{2}$ fluxes using ship observation of surface ocean $\mathrm{pCO}_{2}$ in a simplified biogeochemical offline model. Tellus Ser B Chem Phys Meteorol 62(5):821-840. https://doi.org/10.1111/j.1600-0889.2010.00495.x

Wakita M, Watanabe S, Honda M, Nagano A, Kimoto K, Matsumoto K, Kitamura M, Sasaki K, Kawakami H, Fujiki T, Sasaoka K, Nakano Y, Murata A (2013) Ocean acidification from 1997 to 2011 in the subarctic western North Pacific Ocean. Biogeosciences 10:7817-7827

Yasuda I (1997) The origin of the North Pacific Intermediate Water. J Geophys Res 102(C1):893-909

Yasuda I (2004) North Pacific Intermediate Water: progress in SAGE (SubArctic Gyre Experiment) and related projects. J Oceanogr 60:385-395. https://doi.org/10.1023/B:JOCE.0000038344.25081.42

Yasunaka S, Nojiri Y, Nakaoka S, Ono T, Mukai H, Usui N (2013) Monthly maps of sea surface dissolved inorganic carbon in the North Pacific: basin-wide distribution and seasonal variation. J Geophys Res Oceans 118:3843-3850. https://doi.org/10.1002/jgrc.20279

Publisher's note Springer Nature remains neutral with regard to jurisdictional claims in published maps and institutional affiliations. 